\title{
Standardizing to focus knowledge and improve communication on spinal cord care around the world
}

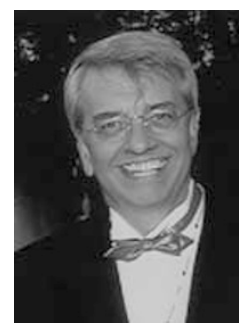

\author{
JJ Wyndaele, Editor \\ F Biering-Sörenson, Assistant Editor \\ Antwerp University Hospital, Antwerp, Belgium \\ E-mail: spinalcord@uza.be
}

Dear Spinal Cord reader,

In this time of globalization and international communication, where sending a paper or news item from one part of the world to the opposite can be done in seconds, the spreading of information has changed dramatically. This has created new challenges. The amount of data has increased so much that reading everything in detail is practically impossible. Choices have to be made. Standards are a good way to facilitate communication without confusion. The International Standards for Neurological Classification of Spinal Cord Injury (ISNCSCI) has, for years, been the basic standard used in studies on individuals with spinal-cord injury (SCI) when characterizing the neurological level and severity of the spinal cord damage. It has also become universal and important to know the American Spinal Injury Association (ASIA) Impairment Scale (AIS) A-E of the individuals with SCI included in the various studies, making comparisons between studies easier and more relevant. The notation to be used for a particular individual with SCI may thus be C5 AIS B, that is an individual with SCI in whom the last normal functioning spinal cord segment is the 5th cervical and the severity on the ASIA Impairment Scale is grade B. It is important that all presenters, authors, reviewers and editors adhere to this way of presenting.

International SCI Data Sets are published steadily in Spinal Cord and it is important that authors are aware of these consensus standards based on the available knowledge. Projects carried out in spinal cord injuries should always consult the possible relevant data sets and, when appropriate, include variables from these. This will in the future provide far more possibilities for comparisons between patients, centres and countries. The development of further International SCI Basic Data Sets continues and some are currently in the approval process. Everyone interested is most welcome to comment on the data sets, both during the process of development and afterwards. This is possible as all data sets, before final approval, have been and will in the future be posted on the web sites of the International Spinal Cord Society (ISCoS) (http://www.iscos.org.uk/) and the American Spinal Injury Association (ASIA) (http://www.asia-spinalinjury.org/bulletinBoard/dataset.php). In addition, when finally approved, all the International SCI Data Sets are available on the ISCoS and ASIA web sites.

In this issue of Spinal Cord, several important manuscripts are included on different topics.

Enjoy them.

- International Standards for Neurological Classification of Spinal Cord Injury. J Spinal Cord Med 2003; 26: S50-S56.

- International Spinal Cord Injury Data Sets. Spinal Cord 2006; 44: 530-534.

- International Spinal Cord Injury Core Data Set. Spinal Cord 2006; 44: 535-540.

- International Lower Urinary Tract Function Basic Spinal Cord Injury Data Set. Spinal Cord 2008; 46: 325-330.

- International Urodynamic Basic Spinal Cord Injury Data Set. Spinal Cord 2008; 46: 513-516.

- The International Spinal Cord Injury Pain Basic Data Set. Spinal Cord 2008; e-pub ahead of print 6 June 2008.

- International Bowel Function Basic Spinal Cord Injury Data Set. Spinal Cord 2008; e-pub ahead of print 26 August 2008.

- International Bowel Function Extended Spinal Cord Injury Data Set. Spinal Cord 2008; e-pub ahead of print 26 August 2008.

- International Urinary Tract Imaging Basic Spinal Cord Injury Data Set. Spinal Cord (accepted). 